\title{
A rare case of Meckel Gruber syndrome
}

\section{Rudrika Chandra ${ }^{1 *}$, Bhanu Pratap Singh ${ }^{1}$, Sanjay Singh ${ }^{2}$}

\begin{abstract}
${ }^{1}$ Department of Obstetrics and Gynaecology, 9 Air Force Hospital Halwara, Ludhiana, Punjab, India ${ }^{2}$ Department of Obstetrics and Gynaecology, Base Hospital Delhi Cantt, Delhi, India
\end{abstract}

Received: 26 April 2019

Revised: 31 May 2019

Accepted: 05 June 2019

\author{
*Correspondence: \\ Dr. Rudrika Chandra, \\ E-mail: rudrika21@gmail.com
}

Copyright: (C) the author(s), publisher and licensee Medip Academy. This is an open-access article distributed under the terms of the Creative Commons Attribution Non-Commercial License, which permits unrestricted non-commercial use, distribution, and reproduction in any medium, provided the original work is properly cited.

\begin{abstract}
Meckel Gruber syndrome (MGS) is a rare lethal autosomal recessive disorder. It is characterized by triad of features having occipital meningoencephalocele, polycystic kidneys and post-axial polydactyly. We report an antenatal patient detected with occipital meningoencephalocele in foetus on early anomaly scan at 15 weeks of gestation followed by foetal MRI which revealed the typical triad features strongly suggestive of MGS. The patient opted for medical termination of pregnancy and the abortus was autopsied, with the permission of the patient, for detailed evaluation of anomalies which were consistent with MGS. This case highlights the importance of a detailed foetal evaluation antenatally to detect anomalies which are incompatible with life and proper diagnosis as it has bearing on patient's future obstetric outcome.
\end{abstract}

Keywords: Meckel Gruber Syndrome, Meningoencephalocele, Polycystic Kidney, Postaxial Polydactyly

\section{INTRODUCTION}

Meckel Gruber syndrome (MGS) was first described by Johann Friedrick Meckel in 1822. In 1934, G.B. Gruber published reports on individuals with Meckel syndrome (MKS) and named the disorder as dysencephalia splanchnocystica. ${ }^{1-4}$ It is a rare, lethal, ciliopathic genetic disorder with autosomal recessive inheritance characterizedby renal cystic dysplasia, central nervous system malformations, polydactyly, hepatic developmental defects and pulmonary hypoplasia secondary to oligohydramnios. $^{5-8}$ It has wide phenotypic variations showing abnormalities of lip, palate, eye, ductal plates of the liver, cardiovascular and genital systems. ${ }^{7,8}$ Other variants described include MKS2 in the Middle East and Northern African families, and recently MKS3 ${ }^{3}$ A high incidence of MKS has been reported in Gujarati Indians. ${ }^{5}$ Authors report a case of MGS suspected in the second trimester antenatal ultrasonogram examination which was further evaluated by foetal MRI and a strong possibility of foetal MKS was considered and the couple was counselled for termination of pregnancy.

\section{CASE REPORT}

A 26-year-old G3P1L1A1 lady of Gujarati descent, with non-consanguineous marriage, presented at 15 weeks of gestation for routine antenatal check-up. Transabdominal ultrasound showed a single live foetus at 15 weeks of gestation, placenta fundo-posterior, liquor grossly reduced and an occipital bony defect measuring 0.8 $\mathrm{cmX} 0.8 \mathrm{~cm}$ with herniation of brain (Figure 1). Foetal MRI was done for detailed foetal evaluation as it could not be performed properly by ultrasound due to decreased liquor. MRI confirmed the presence of occipital encephalocele with herniation of cranial contents and 
revealed additional findings of polydactyly involving all four limbs and bilateral polycystic kidneys. She had history of severe oligohydramnios in previous pregnancy detected at 18 weeks of gestation followed by spontaneous abortion. There was no documentation of the findings of previous pregnancy.

The triad of features in current pregnancy were strongly suggestive of MGS and the couple was counselled for termination of pregnancy in view of $100 \%$ mortality with this condition, which was subsequently done with Misoprostol.

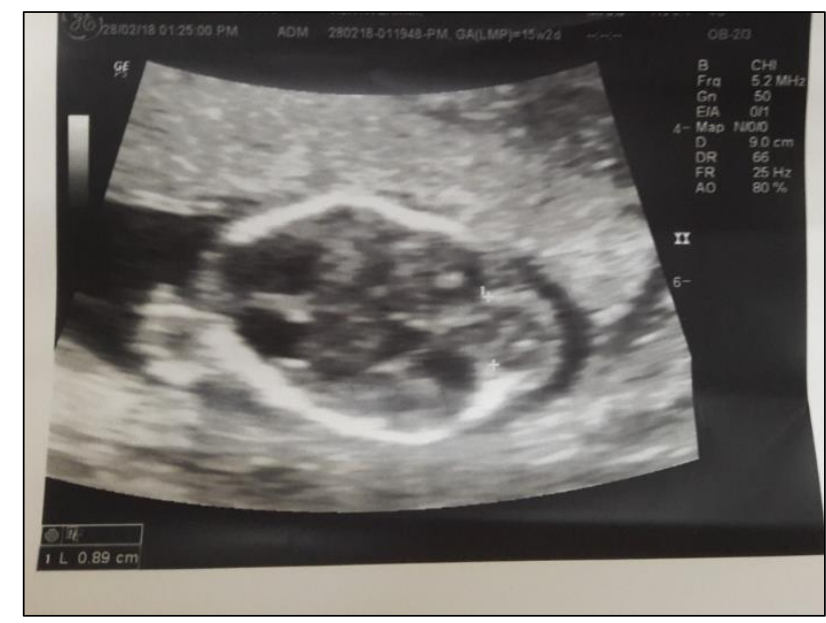

Figure 1: USG of fetal skull showing $8 \mathrm{~mm} \times 8 \mathrm{~mm}$ defect in occiput with outpouching of cranial contents suggesting occipital encephalocele.

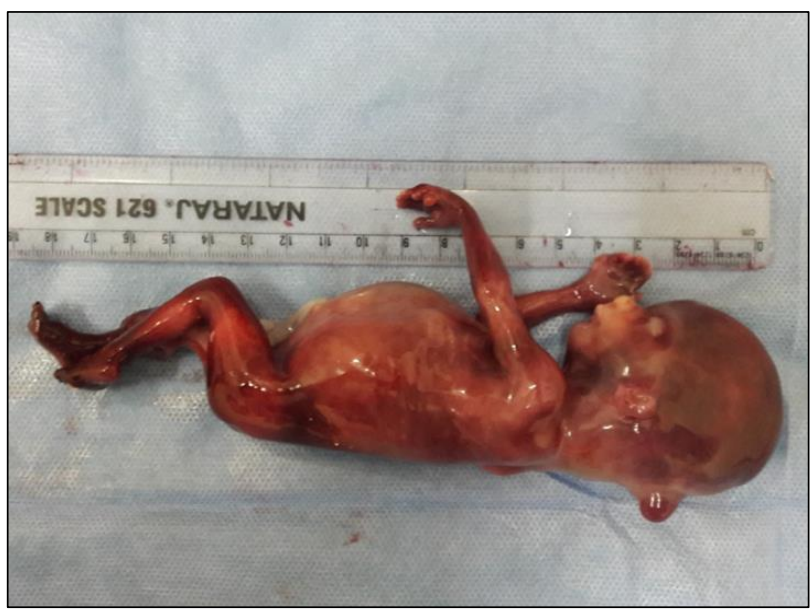

Figure 2: Side view of abortus showing occipital encephalocele.

A dead male abortus with macerated skin measuring 20 $\mathrm{cm}$ in length and weighing $90 \mathrm{gm}$ was delivered. A closed neural tube defect (NTD) was identified in occiput consistent with our radiological finding of occipital encephalocele. A bony defect in occiput measuring $0.8 \times 0.8 \mathrm{~cm}$ with outpouching of contents of the brain covered with membranes was documented on side view and posterior view of the abortus (Figure 2, 3).

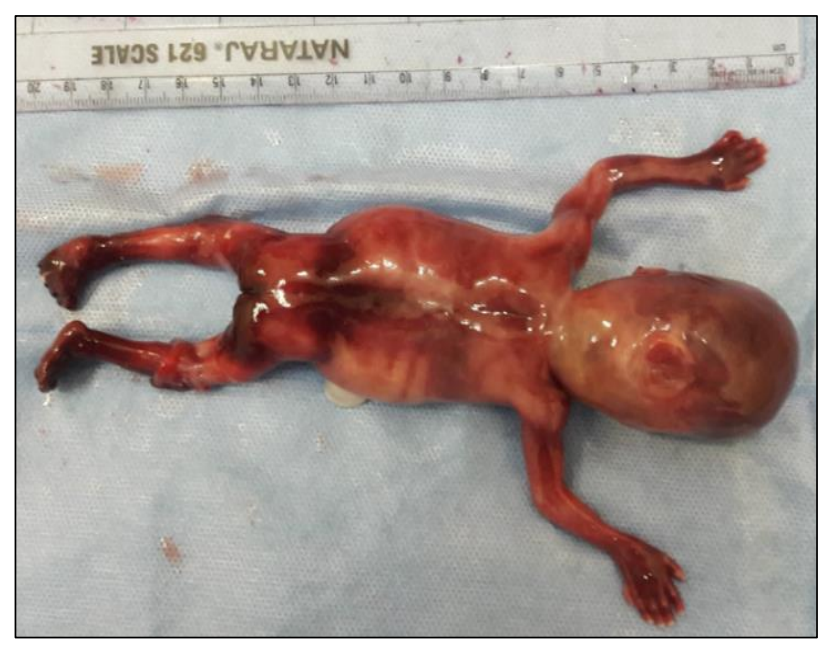

Figure 3: Posterior view of abortus showing occipital encephalocele.

The abdomen was distended with thinned out abdominal wall likely due to enlarged polycystic kidneys occupying the abdominal cavity and compressing the abdominal wall (Figure 4).

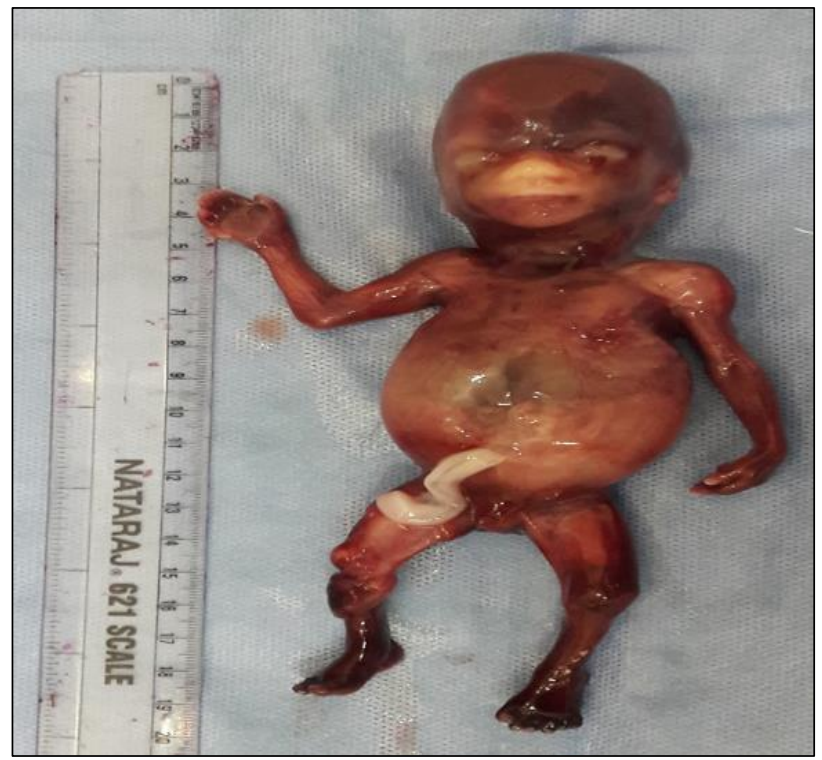

Figure 4: Distended Abdomen of abortus with micrognathia.

An additional digit on the ulnar margin of both hands and lateral to the $5^{\text {th }}$ toe in both lower limbs was identified signifying postaxial polydactyly involving all 4 limbs (Figure 5, 6).

Foetal autopsy was performed, after taking consent from the patient, for further detailed evaluation of the abortus. The abdominal wall was found to be papery thin with 
intestine compressed onto the anterior abdominal wall due to retroperitoneally enlarged kidneys (Figure 7).

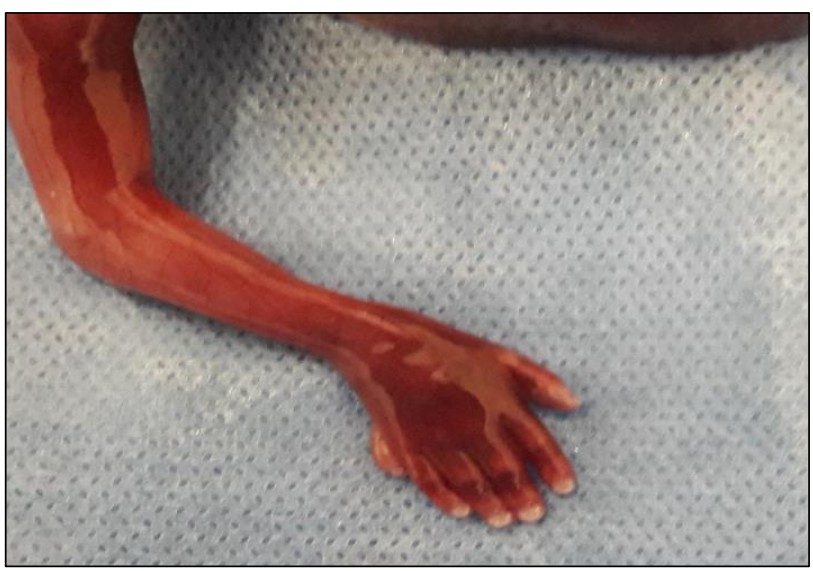

Figure 5: Upper limb of the abortus showing Post Axial Polydactyly.

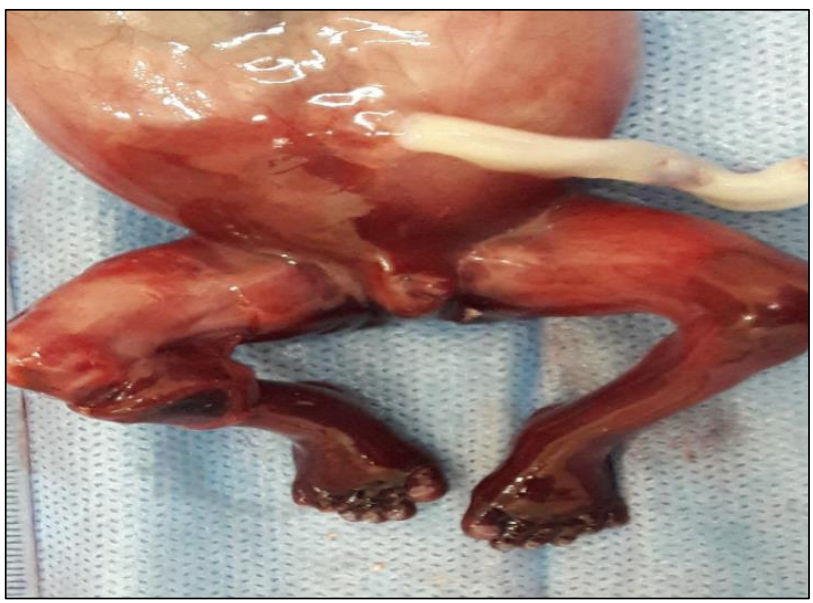

Figure 6: Lower limbs of the abortus showing Post Axial Polydactyly.

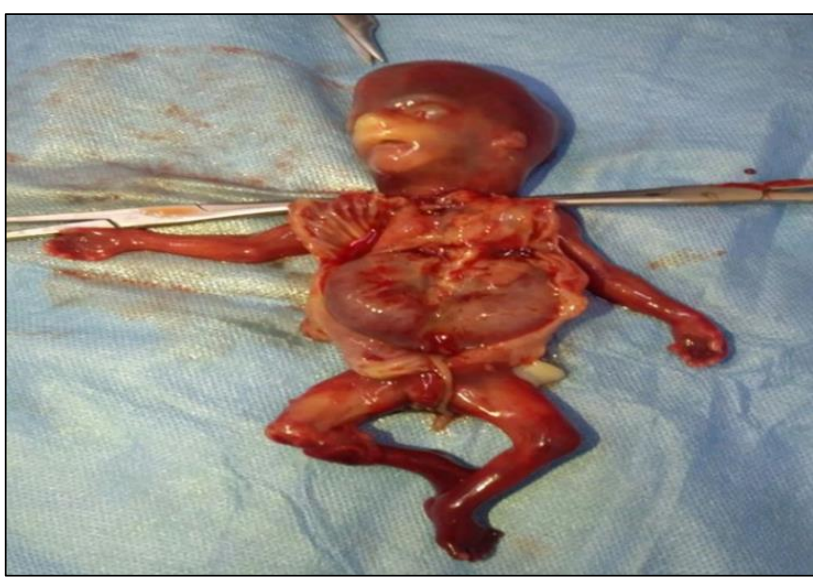

Figure 7: Post-mortem of the abortus showing bilateral polycystic kidney occupying the abdominal cavity completely.
On gross examination, the kidneys measured $3.5 \mathrm{X}$ $3.0 \times 2.5 \mathrm{~cm}$ with smooth external contour and the specimen was sent for histopathological examination (Figure 8). Microscopy of both the kidneys showed numerous cysts lined by a single layer of low cuboidal epithelial cells confirming polycystic kidneys.

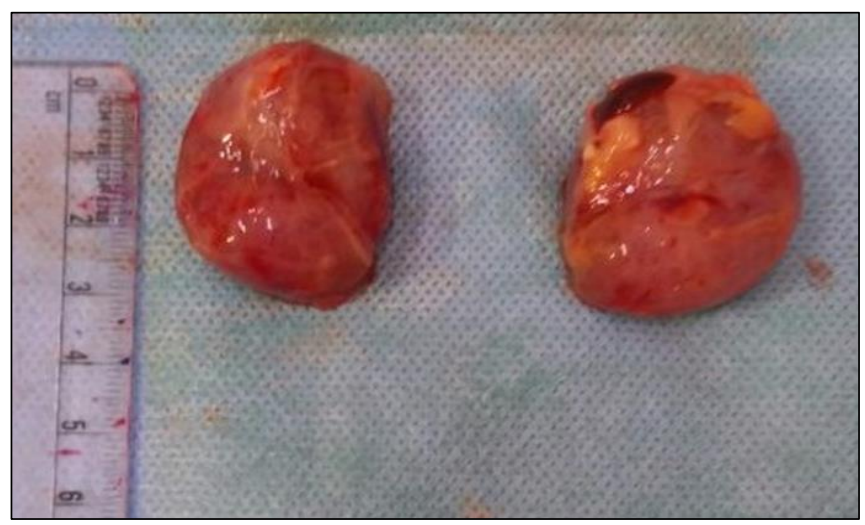

Figure 8: Bilateral Polycystic kidney of the abortus obtained after post-mortem $(3.5 \times 3.0 \times 2.5 \mathrm{~cm})$.

Foetal Karyotype by FISH was performed which ruled out Tri 13. In present case the abortus had occipital encephalocele, polydactyly, cleft palate and bilateral polycystic kidneys. Foetal karyotype by FISH ruled out Trisomy 13.

\section{DISCUSSION}

MGS is prevalent worldwide, with equal male and female sex ratio with around 200 case reports till date., ${ }^{4,8}$ The incidence worldwide has been reported as 1 in 13,250 to 1 in 1,40,000 live births. ${ }^{3}$ The incidence of MGS in Gujarati Indians is as high as 1:1300. MGS is mapped to 6 different loci on different chromosomes 17q21-24 (MGS1), 11q13 (MGS2), 8q21.3q22.1 (MGS3), 12q21.31-q21.33 (MGS4), 16q12.2 (MGS5), and 4p15.3 (MGS6). This mapping suggests genetic heterogeneity.

Meckel-Gruber syndrome is a condition that belongs to ciliopathies, a category of diseases thought to be caused by dysfunction of cilia and flagella. ${ }^{9,10}$ Other known ciliopathies include primary ciliary dyskinesia, BardetBiedl syndrome, Alstromsyndrome, Joubert syndrome, polycystic kidneys and liver disease, nephronophthisis and some forms of retinal degeneration. The central nervous system (CNS) malformation ranges from total craniorachischisis to a partial defect of the corpus callosum. In CNS, the most typical malformation is microcephaly with a sloping forehead and occipital meningoencephalocele. The occipital encephalocele results from an apical defect of the occipital bone or enlarged posterior fontanelle. ${ }^{3}$ The abnormalities of the head and neck such as anencephaly, cerebral or cerebellar hypoplasia, hydrocephalus with or without Arnold-Chiari malformation, absence of olfactory tract or lobe, absence of corpus callosum and septum pellucidum may also be 
seen in this condition. Microphthalmia, cleft palate, micrognathia, ear abnormalities and short neck may also be seen. ${ }^{3}$ The kidneys are grossly enlarged by midtrimester due to cystic changes. ${ }^{3,5,8}$ Cystic dysplasia of the kidneys is the most constant characteristic feature of MGS. Due to this, there is oligo-hydramnios and pulmonary hypoplasia which is the main cause of death. Kidneys may be enlarged 10-20 times the normal size. Postaxial polydactyly is a frequent finding in MGS. Club foot is common because of oligo or anhydramnios.

Other organ involvement includes intrahepatic bile duct anomalies and fibrotic changes in the portal areas of the liver, duct dilatation and periductal fibrosis in pancreas, hypoplastic or ambiguous genitalia, congenital heart defects, cleft lip and palate. Malformations like cleft lip, cleft palate, polydactyly, syndactyly and congenital heart defect occur in relatives of MGS more frequently than expected. ${ }^{8}$

Chromosome analysis is essential to exclude trisomy 13 , which mimics Meckel-Gruber syndrome. Trisomy 13 carries a $1 \%$ recurrence risk, as opposed to the $25 \%$ recurrence rate for Meckel-Gruber syndrome. Linkage or mutation analysis is not yet available. The mortality is $100 \%$ and most babies die in utero or shortly after birth. Pulmonary hypoplasia is the leading cause of death and other causes include liver and renal failure.

\section{CONCLUSION}

MGS is rarely encountered in clinical practice and diagnosed incidentally on antenatal ultrasound evaluation. A detailed family history, accurate prenatal diagnosis with ultrasonography and measurement of alpha-fetoprotein levels in amniotic fluid are essential in diagnosing MGS.

In pregnancy complicated by MGS, counselling for abortion and evaluation of recurrence risk in the future pregnancies are important. In conclusion, Meckel-Gruber syndrome is a rare autosomal recessive condition that has $100 \%$ mortality, the diagnosis should be made possible antenatally with modern ultrasound techniques and the parents should be fully counselled regarding the recurrence risk in future pregnancies.
Funding: No funding sources Conflict of interest: None declared

Ethical approval: Not required

\section{REFERENCES}

1. Gruber GB. Contributions to the question of "coupled" malformations (acrocephaly syndactyly and Dysencephalia splanchnocystica). Contribution Pathol Anat. 1934;93:459-79.

2. Meckel JF. Description of two siblings distorted by very similar deviations. Dtsch Arch Physiol. 1822;7:99-172.

3. Ramachandran U, Malla T, Joshi KS. Meckel-Gruber syndrome-case note. Kathmandu University Medical Journal 2006;4(3), 15:334-6.

4. Salonen R, Paavola P. Meckel syndrome. J Medi Genet. 1998;35(6):497-501.

5. Young I D, Rickett AB, Clarke M. High incidence of Meckel's syndrome in Gujarati Indians. J Med Genet. 1985;22(4):301-4.

6. Wright C, Healicon R, English C, Burn J. Meckel syndrome: what are the minimum diagnostic criteria? J Med Genet. 1994;31(6):482-5.

7. Sudan MS, Gupta S, Sharma N, Nargotra RC. Meckel-Gruber Syndrome: Sonographic DetectionCase report. JK Science. 1999;1(1):30-2.

8. Fried K, Liban E, Lurie M, Friedman S, Reisner SH. Polycystic Kidneys Associated with Malformations of the Brain, Polydactyly and Other Birth defects in Newborn Sibs. J Med Genet.1971;8(3):285-90.

9. Paavola P, Salonen R, Weissenbach J. The locus for Meckel syndrome with multiple congenital anomalies maps to chromosome 17q21-q24. Nat Genet. 1995;11(2):213-5.

10. Badano JL, Mitsuma N, Beales PL. The ciliopathies: an emerging class of Human Genetic Disorders. Annu Rev Genomics Hum Genet. 2006;7:125-48.

Cite this article as: Chandra R, Singh BP, Singh S. A rare case of meckel gruber syndrome. Int J Reprod Contracept Obstet Gynecol 2019;8:2919-22. 